DOI: https://doi.org/10.47405/mjssh.v6i10.1109

\begin{tabular}{|c|c|}
\hline & Malaysian Journal of Social Sciences and Humanities (MJSSH) \\
\hline Malaysian Journal of & Volume 6, Issue 10, October 2021 \\
\hline (Mulssh) & e-ISSN : 2504-8562 \\
\hline & $\begin{array}{l}\text { Journal home page: } \\
\text { www.msocialsciences.com }\end{array}$ \\
\hline
\end{tabular}

\title{
Motif Alam Melayu dalam Puisi-Puisi Terpilih Zurinah Hassan Sebagai Satu Retrospeksi Bahasa Pada Masa Kini
}

\author{
Ros Anita Kartini Mohamed', Abdul Halim Ali' \\ ${ }^{1}$ Fakulti Bahasa dan Komunikasi, Universiti Pendidikan Sultan Idris (UPSI), Tanjong Malim, Perak, Malaysia
}

Correspondence: Ros Anita Kartini Mohmaed (ros_kartini@yahoo.com)

\begin{abstract}
Abstrak
Makalah ini menganalisis puisi-puisi Zurinah Hassan dengan memberi tumpuan kepada motif alam Melayu yang terdapat di dalamnya. Oleh yang demikian, perbincangan makalah ini adalah untuk memperlihatkan bagaimana keunikan motif alam Melayu menjadi satu retrospeksi apabila diucapkan kembali oleh penyair dalam puisi-puisi moden dengan penggayaan struktur yang lazim digunakan dalam puisi tradisional, yakni kabahasaannya sebagai satu pernyataan pascakolonial. Motif alam Melayu ini dirakamkan kembali sebagai satu bentuk retrospeksi pascakolonial oleh Zurinah Hassan menerusi puisi-puisi terpilih sama ada secara perseorangan atau menerusi antologi puisi Zurinah Hassan iaitu Kumpulan Puisi Sesayup Jalan (1974), Kumpulan Puisi Di Sini Tiada Perhentian (1977), Kumpulan Puisi Keberangkatan (1985), Kumpulan Puisi Pujangga Tidak Bernama (1994), Antologi Nota Waktu (2000), Kumpulan Puisi Pesanan dari Gunung Ledang (2004) dan yang terakhir Kumpulan Puisi Salasilah (2005). Kajian ini menggunakan kaedah kualitatif kajian kepustakaan dengan menganalisis teks. Penggunaan motif alam Melayu dalam puisi-puisi kajian merupakan suatu usaha peribumi pascakolonial di alam Melayu mendokumentasikan kembali, sekali gus menjulang budaya leluhurnya ke mata dunia menggunakan bahasa kebangsaan peribumi.
\end{abstract}

Kata kunci: motif, alam Melayu, retrospeksi, pascakolonial, puisi

\section{Malay Nature Motifs in Selected Poems of Zurinah Hassan as A Retrospection of Language in The Present}

\begin{abstract}
This paper analyzes the poems of Zurinah Hassan by focusing on the motifs of the Malay world found in them. Therefore, the discussion of this paper is to show how the uniqueness of Malay natural motifs becomes a retrospective when recited by poets in modern poems with structural styling commonly used in traditional poetry, namely its language as a postcolonial statement. This Malay motif was rerecorded as a form of postcolonial retrospective by Zurinah Hassan through selected poems either individually or through Zurinah Hassan's anthology of poems, namely Kumpulan Puisi Sesayup Jalan (1974), Kumpulan Puisi Di Sini Tiada Perhentian (1977), Kumpulan Puisi Keberangkatan (1985), Kumpulan Puisi Pujangga Tidak Bernama (1994), Anthologi Nota Waktu (2000), Kumpulan Puisi Pesanan dari Gunung Ledang (2004) and the last Kumpulan Puisi Salasilah (2005). This study uses a qualitative method of literature review by analyzing the text. The use of Malay motifs in the study poems is a postcolonial indigenous effort in the Malay world to re-document, as well as elevate their ancestral culture to the eyes of the world using the indigenous national language.
\end{abstract}


Keywords: motif, the Malay world, retrospect, postcolonial, poetry

\section{Pengenalan}

Menyoroti puisi-puisi terpilih Zurinah Hassan, kajian mendapati nilai kesusasteraan merupakan cara utama yang digunakan oleh Zurinah Hassan untuk menyerlahkan pernyataan pemikiran pascakolonialnya. Penggunaan nilai-nilai kesusasteraan dalam puisi-puisi kajian memperlihatkan keyakinan Zurinah Hassan untuk mengedepankan tradisi dalam konteks pengucapan kini sesuai dengan mesej yang ingin disampaikan. Usaha mengedepankan kembali unsur tradisi dalam puisi-puisi kajian ini sekali gus memperlihatkan kecintaan Zurinah Hassan terhadap nilai-nilai tradisi ke arah mengukuhkan matlamata kepenyairan pascakolonialnya yang menggunakan bahasa sebagai maklumat. Untuk tujuan itu, kajian telah mengenal pasti beberapa nilai kesusasteraan yang bersesuaian telah digunakan oleh Zurinah Hassan untuk menyampaikan pemikiran pascakolonial tersebut. Antara nilai kesusasteraan yang diangkat oleh beliau ialah motif alam Melayu. Dengan menampilkan motif alam Melayu dalam puisi-puisi terpilih kajian menguatkan pernyataan pascakolonial Zurinah Hassan apabila ianya digunakan kembali pada masa kini untuk merungkaikan agenda kolonial bagi tatapan generasi kini. Pada masa yang sama, tindakan Zurinah Hassan ini adalah retospeksi pada masa kini.

\section{Sorotan Literatur}

Malaysia merupakan salah sebuah negara Asia yang tidak terkecuali daripada mengalami penjajahan kuasa Barat. Ketika berlakunya kemerosotan sejarah dari segi politik, negara-negara Nusantara telah memperlihatkan kekayaannya dari segi budaya, khususnya kesusasteraan Melayu dan Jawa (1995). Karya-karya yang dihasilkan pada ketika itu cenderung menonjolkan kekuatan dalaman dengan mengadun unsur-unsur tradisi lisan dengan modeniti. Penjajahan dikatakan telah meninggalkan kesan yang amat negatif ke atas sistem ekonomi, politik dan sosial masyarakat tempatan. Malaysia juga menerima tempias arus pascakolonial seperti negeri-negeri tanah jajahan yang lain. Penjajah juga secara tidak langsung telah meninggalkan kesan psikologi kepada pemikiran masyarakat tempatan, terutamanya dalam kalangan masyarakat di luar bandar. Secara tidak langsung, penjajahan dilihat turut memberi kesan terhadap perkembangan kesusasteraan Melayu di Malaysia. Hal ini kerana, Malaysia juga menerima nasib yang sama seperti negara-negara tanah jajahan yang lain, apabila retorik kolonial telah digunakan untuk mengawal kaitan kuasa antara yang dijajah dengan yang menjajah sambil mengetepikan budaya peribumi dan meletakkan ciri-cirinya di pinggir teks (1994). Penjajah cenderung menonjolkan kewibawaan golongan kulit putih yang dianggap sebagai pencetus tamadun dan pentadbiran di Malaysia. Lantaran itu, teks yang dihasilkan oleh mereka cenderung mengagungkan kehebatan bangsa mereka untuk mengukuhkan konsep 'white man's burden' nya. Hubungan antara yang dijajah dengan penjajah menjadi lebih rumit dalam dunia kesusasteraan apabila pada masa yang sama penulis-penulis Melayu tradisional pula terlalu memberi tumpuan kepada karya yang berdasarkan sumber historiografi Melayu tradisional (1983). Di antara karya-karya tradisional yang terhasil termasuklah Hikayat Raja-raja Pasai (Samudera Pasai), Sejarah Melayu (Melaka), Misa Melayu (Perak), Hikayat Merong Mahawangsa (Kedah) dan Salasilah Melayu Dan Bugis (Johor). Kesedaran ini ada hubungannya dengan sejarah pertumbuhan peribumi (Malaysia) itu sendiri dengan jatuh bangunnya dalam menghadapi kolonialisme (1990). Pengalaman yang dihadapi dalam tempoh penjajahan itu telah menumbuhkan satu kesatuan bangsa yang baru selepas merdeka yang dikenali sebagai era pascakolonial. Bangsa baru itu seterusnya bertanggungjawab memelihara kemerdekaan tersebut dengan nilai-nilai baru tanpa menyingkirkan nilai tradisi dan rohaniah bagi pembinaan keperibadian yang lebih bererti melalui penghasilan karya.

Kajian mendapati, kesedaran ini telah diguna oleh penyair untuk turut sama merealisasikan agenda wacana pascakolonial. Justeru penyair kelihatan berkeupayaan untuk mengungkapkan dan mentakrifkan gagasan serta pengertian sendiri sebagai landasan kewujudan sastera tanpa ditakrifkan dan digabungkan dalam diri dan kerangka pemikiran Barat (2005). Dengan ini juga akan 
memperkayakan lagi motif pengembalian kepada proses pembinaan jati diri yang menjadi matlamat penciptaan puisi oleh penyair. Proses ini sekali gus, memperlihatkan kekuatan penyair dalam usaha melawan wacana kolonial.

Bertolak daripada kesedaran inilah Zurinah Hassan sebagai penyair wanita tersohor cuba membangkitkan semula jati diri dalam kalangan peribumi yang telah berkubur ekoran daripada penjajahan dengan menggunakan kembali unsur tradisi, yang dapat dikenal pasti melalui puisi-puisi kajian. Justeru itu, setiap unsur tradisi yang dimunculkan dalam puisi-puisi kajian ini adalah berfokuskan motif untuk memulihkan semula semangat dan jati diri peribumi yang telah dihancurkan oleh penjajah. Keadaan ini memang diterima dalam kesusasteraan pascakolonial yang melihat unsur tradisi sebagai sumber inspirasi sama ada dari segi bentuk atau isinya untuk menjadi sumber subversif bagi menggugat wacana kolonial (2003). Bagi mencapai maksud tersebut, kajian ini mendapati bahawa puisi-puisi kajian yang dihasilkan oleh penyair iaitu, Zurinah Hassan cenderung memperlihatkan usahanya kembali kepada tradisi sebagai usaha menguatkan lagi sumber kepenyairan dalam penghasilan puisi. Malahan, penggunaan kembali unsur tradisi dalam puisi-puisi kajian ini telah dilihat dalam bentuk yang lebih kompleks. Setiap simbol tradisi yang ditonjolkan dalam puisi-puisi kajian, sebenarnya merupakan pernyataan pascakolonial Zurinah Hassan untuk menolak wacana pascakolonial. Dalam perhubungan ini, Zurinah Hassan cuba membawa semula generasi kini berfantasi memasuki ruang kolonial yang boleh mendedahkan hubungan dialektis, persis pahit manis, madu dan racun semata-mata untuk menunjukkan kejelakan perbuatan penjajah dan kesannya ke atas peribumi sehingga kini (2005). Lebih jitu dikatakan bahawa simbol tersebut digunakan oleh Zunirah sebagai pernyataan pascakolonial apabila cuba menginterpretasikan suasana semasa khususnya fenomena yang berlaku selepas kemerdekaan di Malaysia sebagai tanda protes peribumi terhadap mantan penjajahnya melalui puisi-puisi kajian.

\section{Pernyataan Masalah}

Pada dasarnya, terdapat beberapa perkara yang mendorong kajian ini dilakukan secara mendalam. Pertamanya kajian mendapati, kecenderungan Zurinah Hassan menggunakan motif alam Melayu dalam puisi-puisi yang dihasilkan. Usaha penyair sedemikian merupakan satu proses retrospeksi untuk memperkayakan khazanah kesusasteraan Melayu kini dalam kalangan generasi Y dan Z. Hal ini kerana, kajian mendapati kesukaran untuk menentukan antara bentuk pengucapan moden dengan klasik dalam kalangan generasi kini. Hal ini berlaku kerana kebanyakan generasi Y dan Z lebih meminati kursus yang bersifat praktikal dan memenuhi kehendak atau pasaran semasa (2017).

Seterusnya, kajian mendapati proses retrospeksi motif alam Melayu dalam puisi-puisi moden oleh penyair begitu ketara walhal tindakan ini dilihat sebagai sesuatu yang klise dan dianggap tidak bersifat komersial dalam kalangan generasi $\mathrm{Y}$ dan $\mathrm{Z}$ yang membaca puisi-puisi tersebut. Hal ini tentulah tidak benar dan bertentangan dengan fungsi puisi dalam masyarakat yakni untuk menyampaikan maklumat. Memandangkan motif alam Melayu boleh dihubungkaitkan dengan wacana pascakolonial, maka motif alam Melayu yang diungkapkan oleh penyair masa kini itu boleh dibaca dan dikaji sebagai satu cara pengungkapan pascakolonial bagi memahami mesej yang ingin disampaikan oleh penyair.

\section{Objektif Kajian}

Objektif kajian ini adalah untuk menyedarkan masyarakat bahawa penggarapan semula unsur tradisi oleh penyair masa kini merupakan agenda pascakolonial. Seterusnya kajian ini menjadi pelengkap kepada kajian-kajian lain yang ada berhubung pengungkapan kembali unsur tradisi sebagai satu perjalanan retrospeksi penyair pada masa kini. 


\section{Teori Kajian}

Pascakolonial sebagai sebuah kajian muncul pada 1970-an. Kajian Pascakolonial di Barat salah satunya ditandai dengan kemunculan buku Orientalisme (1978) karya Edward Said yang kemudian disusuli dengan sejumlah buku lainnya yang masih terkait dengan perspektif Barat dalam memandang Timur. Buku-buku Said seperti Covering Islam: How the Media and the Experts Determine How We See the Rest of the World (1981) dan Culture and Imperialism (1993) merupakan sekuel dari buku Orientalisme tersebut. Buku semacam The Empire Writes Back (1989) suntingan Bill Ashcroft, Gareth Griffiths, dan Helen Tiffin merupakan buku lain yang sering dijadikan rujukan dalam pembahasan teori pascakolonial.

Seperti yang diungkap Said dalam Orientalisme, ada sejumlah karya sastera dalam dunia Barat yang turut memperkuat hegemoni Barat dalam memandang Timur (Orient). Sejumlah karya seni itu telah melegitimasikan praktik kolonialisme bangsa Barat atas kebiadaban Timur. Penjajahan adalah sesuatu yang alamiah, bahkan semacam tugas bagi Barat untuk memperadabkan bangsa Timur.

Menurut Said (2002) kebudayaan dan politik pada zaman kolonialisme telah bekerjasama, secara sengaja atau pun tidak, hingga melahirkan suatu sistem dominasi yang melibatkan bukan hanya meriam dan serdadu tetapi suatu kedaulatan yang melampaui bentuk- bentuk, kiasan dan imaginasi penguasa dan yang dikuasai. Hasilnya adalah suatu visi yang menegaskan bahwa bangsa Eropah bukan hanya berhak, melainkan wajib untuk berkuasa. Ini membawa kepada kekuasaan imperial Barat menemui perlawanannya. Kekuasaan ini mewujudkan perhubungan timbal balik (reciprocal) antara kaum penjajah dan terjajah. Mereka akan hidup bersama dan saling berperang, dan merakamkan kembali kisah-kisah "perlawanan" dalam diri para penulis pascakolonial seperti Fanon, C.L.R. James, Yeats, Chinua Achebe, dan Salman Rusdhie. Dalam dunia pascakolonial sekarang ini, Said (1995) mengajukan sanggahan terhadap hujahan-hujahan yang mengatakan bahwa kebudayaan dan identiti kebangsaan adalah satu bentuk yang tunggal dan mumia seperti yang dipaparkannya dalam buku Culture and Imperialism (yang diindonesiakan oleh Penerbit Mizan menjadi Kebudayaan dan Kekuasaan).

Dalam makalah ini, kajian ini menggunakan model sastera kebangsaan Asccroft sebagai kerangka teoritis kajian. Karya yang tergolong dalam model sastera kebangsaan ini, mempunyai tiga ciri khas (1986), iaitu:

i. Model kebangsaan yang berasaskan "Kreol”, model ini memfokuskan kepada karya-karya yang diperjuangkan oleh kaum yang berketurunan Eropah di Hindia Barat. Karya-karya yang dihasilkan menurut Partha Chatterjee merupakan karya-karya yang berbentuk "pilgrim creole funtionaries" dan "provincial creole printmen".

ii. Model kebangsaan yang berasaskan "bahasa" kebangsaan Eropah. Menurut Partha Chatterjee, model ini sinonim dengan konsep "available for pirating" di kalangan negara-negara yang telah mengalami proses kemerdekaan. Karya-karya kesusasteraan yang dihasilkan di bawah lingkungan model ini merupakan karya-karya yang cuba menolak budaya penjajah melalui perjuangan bahasa kebangsaan sendiri.

iii. Model ketiga ialah model yang berasaskan "semangat kebangsaan". Model ini dirujuk kepada karya-karya yang mengetengahkan tuntutan kesamarataan bangsa Rusia terhadap budaya.

Walaupun ketiga-tiga model di atas hadir dalam kesedaran kebangsaan di negara-negara dunia ketiga pada abad ke-20 tetapi model kedua sahaja yang akan digunakan dalam kajian ini. Model kedua ialah model yang cuba menonjolkan perjuangan melawan balik budaya penjajah melalui bahasa. Sepertimana yang diusahakan oleh pengarang-pengarang di negara Afrika dan India, mereka ini merupakan pengarang yang mewakili masyarakat di negara mereka yakni negara yang pernah dijajah dan telah mendapat kemerdekaan. Model "bahasa" dipilih kerana ia amat bersesuaian dengan objektif kajian yang cuba memperlihatkan bagaimana penyair berusaha mereproduksikan budaya peribumi melalui bahasa yang bersifat ambiguiti. Menurut Wa Thiong'O; 
"Language as communication and as culture are then product of each other: Communications creates culture: culture ia a means of communication. Language carries culture, and culture carries, particularly through orature and literature, the entire body of values by which we come to preceive ourselves and our place in the world. How people perceive themselves affects hoe they look at their culture, at their entire relationship to nature and to other beings. Language is thus inseparable from ourselves as a community of human beings with a specific relationship to the world." (1994).

Petikan di atas jelas telah memperlihatkan telah timbul kesedaran dalam pemikiran Wa Thiong'O yang mewakili peribumi tanah jajahan, bahawa peri pentingnya bahasa dalam kehidupan. Bahasa disifatkan sebagai produk budaya yang meletakkan sesuatu bangsa pada kedudukan asalnya. Dengan erti kata lain, bahasa memainkan peranan yang amat penting dalam membentuk identiti peribumi. Hal ini kerana, dengan bahasa wacana kolonial bertapak dan menyuburkan agendanya dan dengan bahasa juga usaha penyuburan budaya penjajah akan dipatahkan. Dalam hubungan ini, During menyatakan bahawa;

"For the post-colonial to speak or write in the imperial tongue is to call forth a problem of identity, to be thrown into mimicry and ambivalence. The question of language for post-colonialism is political, cultural and literacy...in the material sense that a choice of language is a choice of identity." (1995).

Dalam konteks pascakolonial, menulis atau bertutur dalam bahasa asing dikaitkan dengan permasalahan identiti. Hal ini kerana, bahasa dikatakan mempunyai perhubungan yang jelas dengan politik, budaya serta sastera sesebuah negara. Di sini, bahasa mencerminkan identiti peribumi yang terjajah. Dengan penggunaan model "bahasa" dalam kontinum kebangsaan melalui kajian ini, secara tidak langsung akan menemukan keselarian dengan pemaknaan dekolonisasi yang ditunjang oleh Fanon yang menyatakan;

"Decolonisation is the meeting of two forces, opposed to each other by their very nature, which in fact owe their originality to that sort of substantification which results from and is nourished by the situation in the colonies"

"....It brings a natural rhythm into existence, introduced by new men, and with a new language and a new humanity. Decolonisation is the veritable creation of new men. But this creation owes nothing of its legitimacy to any supernatural power; the "thing" which has been colonised becomes man during the same process by which it free itself' (1966).

Dekolonisasi ialah pertemuan dua buah kuasa yang bertentangan antara satu sama lain secara semula jadi. Persetentangan ini membawa kepada kewujudan irama semulajadi yang datang daripada penutur, bahasa dan kemanusiaan yang baru. Pernyataan ini walaupun disifatkan terlalu radikal namun pemikiran Fanon ini, amat sesuai digunakan untuk mengukuhkan usaha penyair pascakolonial ke arah pengembalian kepada tradisi sebagai suatu proses penyembuhan (recuperation), iaitu pengembalian kepada satu kekuatan untuk membina kembali jati diri. Hal ini amat bersesuaian dengan konsep puisi yang dihasilkan oleh penyair peribumi khususnya selepas kemerdekaan di Malaysia, yang telah menampilkan kepelbagaian unsur tradisi sebagai tanda kecenderungan penyair pascakolonial untuk menjulang kembali identiti leluhurnya yang telah dipinggirkan oleh mantan penjajahnya dahulu. Frantz Fanon (2000), merasakan bahawa kini sudah sampai waktu peribumi berbicara kepada bangsanya, perlu menyusun kalimat yang dapat mengungkapkan isi hati rakyat dan menjadi saluran bagi realiti baru dalam tindakan. Justeru, kini bahasa merupakan senjata yang paling tajam bagi penyair peribumi mematahkan semula agenda penjajah yang dilihat suatu waktu dahulu cuba merobekkan bahasa peribumi di bawah projek dekolonisasi. 
Penglibatan pengarang pascakolonial dengan isu-isu imperialisme dan kolonialisme akhirnya memperlihatkan kecenderungan untuk mencari alternatif kepada budaya dominan semasa. Hal ini telah mendesak para pengarang untuk kembali merenung kepada jati diri, akar budaya tradisi peribumi. Fenomena ini dikenali sebagai satu proses belokan ke dalam yang telah mencetuskan minat baru peribumi untuk mengasimilasikan budaya Barat (1999). Peribumi mula memikirkan tentang peri pentingnya memaut kepada satu budaya sepunya yang dapat memberi identiti kesukuan. Di sini bahasa memainkan peranan yang amat penting dalam usaha memartabatkan kembali identiti sepunya peribumi. Melalui bahasa, masyarakat, peristiwa, produk kebudayaan seperti nilai-nilai tradisi dan simbol-simbol yang dipandang sebagai pembentuk bangsa dan tempat telah diangkat sebagai perwakilan bangsa peribumi untuk menolak kolonial. Hal ini diperkukuhkan lagi dengan kenyataan Ashcoft di bawah:

\section{"The post-colonial text bring language and meaning to a discursive site in which they are mutually constitued, and at this site the importance of usage is inescapable" (1995).}

Pemikiran di atas cuba menjelaskan bahawa tidak semudah yang disangka dalam proses pemberian makna bagi sesuatu perkataan. Dalam erti kata lain, bahasa bukan sahaja alat untuk merakamkan pengalaman tetapi juga cara yang ideal untuk penutur peribumi mentakrifkan kembali pengalaman tersebut. Kecenderungan ini telah digunakan sebaik mungkin oleh penyair era pascakolonial di Malaysia sepertimana yang dirakamkan melalui puisi-puisi yang telah dihasilkan. Misalnya dalam puisi Muhammad Haji Salleh iaitu, "Si Tenggang II" yang telah melahirkan semula legenda pendosa Si Tenggang dalam satu perspektif ruang dan pengalaman manusia Melayu pascakolonial yang bersifat kosmopolitan yakni dikatakan sebagai Melayu yang lebih yakin akan diri dan identiti dirinya. Selain itu, dalam sajak-sajak Sejarah Melayu pula, Muhammad Haji Salleh telah mengangkat kembali mitos kewujudan Bukit Siguntang dengan segala ketakjuban dan kesakralan. Hal ini menjadikan kewujudan Bukit Si Guntang sebagai sesuatu yang realistik dan magis. Merakamkan kembali unsur tradisi secara interteks juga, turut mendapat perhatian Zaihasra, apabila episod Tun Fatimah di dalam Sejarah Melayu telah diceritakan kembali dalam bentuk puisi balada dan dikenali sebagai "Balada Tun Fatimah". Tun Fatimah merupakan watak wanita tradisi yang digambarkan terpaksa mengharungi hidup penuh suka duka sebagai seorang anak Bendahara dan pada masa yang sama menjadi isteri raja Melaka. Motif tradisi hero epik iaitu, Hang Tuah turut menarik perhatian penyair pascakolonial yang lain seperti Qassim Ahmad, lalu dimanifestasikan melalui puisi "Jalan Ke Parlimen". Motif hero epik tersebut cuba dilihat daripada perspektif pascamerdeka yang berbeza (1999).

Pada dasarnya, penerapan bentuk-bentuk tradisi dalam karya-karya kesusasteraan kreatif telah lama dimunculkan oleh penulis-penulis Afrika dalam menghasilkan karya mereka. Penciptaan karya tradisi dalam bentuk modeniti ini adalah garapan daripada pengalaman penjajahan lepas yang berlaku ke atas tanah air mereka (1980). Contoh yang paling jelas adalah percubaan seorang penulis, iaitu Chinua Achebe menangguk peristiwa-peristiwa berbentuk tradisi dan membancuhnya sebagai korpus utama dalam penghasilan karya-karyanya. Misalnya di dalam karyanya Things Fall Apart (1958). Selain Achebe, Ngugi Wa Thiong'O, juga merupakan penulis yang cukup memahami falsafah tradisi dan sastera rakyat Afrika. Ngugi, sebagai penulis yang lahir daripada bumi yang pernah dijajah juga tidak terkecuali daripada daripada memberi perhatian kepada unsur-unsur tradisi dalam menghasilkan karya. Unsur tradisi yang dimaksudkan di sini adalah pemakaian semula bentuk sastera lisan dalam karyakarya moden. Hal ini dapat dilihat daripada cara Ngugi menggarap semula penat jerih bangsa Kenya melawan penjajah. Segala bentuk pengalaman itu kemudiannya diterbitkan dalam karya yang berjudul The River Between (1965). Jelaslah di sini bahawa penggunaan tradisi lisan menjadi suatu yang bersifat integral dalam karya-karya moden apabila Ngugi berjaya menjalinkan dan memunculkan bahan-bahan daripada budaya etniknya ke dalam karyanya itu. Bahan-bahan tersebut merupakan korpus yang diambil melalui penceritaan lisan dan motif-motif naratif rakyat yang ada di Afrika. Tujuan Ngugi jelas, iaitu untuk menghidupkan semula tradisi Afrika sebagai pernyataan pascakolonial terhadap mantan penjajahnya. Tegasnya, kajian ini bertujuan untuk melihat kesan peminggiran karyakarya kesusasteraan peribumi oleh penjajah dan bagaimana pengarang peribumi menerapkan unsurunsur tradisi di dalam karyanya sebagai pernyataan pascakolonial terhadap penjajahnya yang pernah meminggirkan nilai-nilai tradisi dalam budayanya. 


\section{Metod Kajian}

Analisis ini adalah sebuah analisis kepustakaan dengan kaedah penghuraian secara deskriptif berdasarkan kepada puisi-puisi terpilih Zurinah Hassan. Untuk itu, analisis terhadap struktur dalaman dan luaran puisi-puisi terpilih akan dilakukan. Sebanyak lima buah antologi puisi Zurinah Hassan dikaji. Sementara itu, pendekatan sejarah juga digunakan dalam kajian ini. Penggunaan pendekatan ini adalah kerana genre sastera tidak hadir dalam keadaan kekosongan sejarah dan sosialnya (1963).

\section{Hasil Kajian}

Berdasarkan jadual 1, terdapat lima buah teks puisi kajian telah diteliti. Daripada teks puisi kajian tersebut, jelas memperlihatkan bahawa motif alam telah hadir dalam puisi kajian yang diterbitkan melalui antologi Keberangkatan (1985) lagi. Di sini, penyair kelihatan memusatkan perhatian kepada motif alam sebagai suatu yang tradisi dalam berkarya. Demikian, motif alam mula mendapat perhatian penyair melalui sorotan sebuah puisi yang berjudul "Perarakan Suku Abad" (1985). Penyair telah memperlihatkan bahawa motif alam yang digunakan mempunyai perkaitan untuk menginterpretasikan peristiwa sejarah yang telah berlaku dalam konteks kini. Penggunaan unsur alam dan perkaitannya dengan peristiwa sejarah terus memperlihatkan semakin mendapat perhatian penyair bagi puisi-puisi kajian dalam tahun berikutnya apabila berlakunya peningkatan jumlah penggunaan motif alam melalui puisi-puisi kajian yang diterbitkan dalam antologi Nota Waktu (2000) dan Salasilah (2005).

Walau bagaimanapun, motif alam menunjukkan penurunan penggunaannya di dalam puisi-puisi kajian yang dihasilkan melalui antologi Pujangga Tidak Bernama (1994) dan dalam antologi Kumpulan Puisi dari Gunung Ledang: A Message from Mount Ledang: An Anthology of Poems (2004). Hal ini kerana alam dapat disifatkan sebagai suatu yang amat erat hubungannya dengan manusia. Namun keeratan hubungan itu tidaklah bersifat fizikal sahaja tetapi juga bersifat spiritual. Penerapan unsur alam sebagai simbolisme menunjukkan kematangan penyair semakin pasrah, bahawa alam sangat dekat hubungannya dengan kehidupan seseorang. Hubungan sedemikian menimbulkan kesan yang penting, iaitu mempengaruhi serta membentuk kesedaran atau pemikiran, sikap dan jiwa manusia. Hal ini sekali gus mempengaruhi pemikiran penyair dalam usaha menerapkan motif alam dalam puisi-puisi kajian di atas.

Jadual 1: Motif Alam Dalam Puisi-puisi Kajian Zurinah Hassan

\begin{tabular}{ccc}
\hline Tahun & Judul Antologi & Motif Alam \\
\hline $\mathbf{1 9 8 5}$ & Kumpulan Puisi Keberangkatan & 4 \\
$\mathbf{1 9 9 4}$ & Kumpulan Puisi Pujangga Tidak Bernama & 4 \\
$\mathbf{2 0 0 0}$ & Antologi Nota Waktu & 12 \\
$\mathbf{2 0 0 4}$ & Kumpulan Puisi Pesanan dari Gunung Ledang & 3 \\
$\mathbf{2 0 0 5}$ & Kumpulan Puisi Salasilah & 197 \\
\hline Jumlah & & 220 \\
\hline
\end{tabular}

Beberapa motif alam yang kerap diungkapkan oleh penyair, antaranya ialah motif ikan todak. Motif ikan todak secara harafiahnya berhubung langsung dengan kisah Hang Nadim dalam peristiwa Singapura dilanggar Todak sepertimana yang tercatat di dalam Sejarah Melayu. Hang Nadim merupakan budak yang bertanggungjawab menyelamatkan Singapura daripada serangan ikan todak apabila semua rakyat takut untuk berfikir bagi menyelesaikan permasalahan negara. Ini kerana konsep daulat yang dipegang oleh peribumi zaman feudal telah mengikat keeratan hubungan antara rakyat dengan raja tersebut. Sebagai seorang penyair yang peka kepada situasi semasa yang berlaku di tanah airnya, Zurinah Hassan cuba membaca peristiwa serangan todak ini sebagai satu bacaan pascakolonial apabila situasi tersebut cuba diironikan penaksirannya dengan keadaan masyarakat pada ketika ini yang tidak lagi memandang institusi kesultanan Melayu sebagai suatu yang bersifat kudus dan sakral apabila perlembagaan negara telah memaktubkan bahawa raja-raja Melayu turut sama boleh didakwa atas kesalahan yang dilakukan. Sehubungan itu juga peristiwa Hang Nadim yang disifatkan sebagai suatu pengajaran kepada golongan pemerintah telah diangkat oleh penyair sebagai iktibar dalam 
membina perhubungan yang baik antara pemerintah dan yang diperintah di tanah air pada ketika puisi itu dihasilkan. Hal ini dapat dikesani melalui ungkapan "ini tidak yang lain" yang dipetik daripada puisi "Mimpi Paduka Raja" (2005). Ungkapan ini memperlihatkan satu sinisme yang berbaur peringatan oleh penyair kepada peribumi agar mereka tidak alpa dengan kemewahan yang dinikmati sehingga membenarkan penjajahan berulang kembali.

Dalam perhubungan ini, penyair mengidentifikasikan bahawa, sogokan kemewahan dan pemodenan kesan daripada pengenalan teknologi dari luar tidak mustahil akan mengembalikan proses dekolonisasi penjajah ke atas peribumi pada masa kini. Titik kesedaran ini menyematkan rasa bertanggungjawab penyair untuk menyedarkan peribumi, supaya bersedia di segenap sudut, untuk berhadapan dengan sebarang kemungkinan penjajahan yang berbentuk minda melalui teknologi yang diperkenalkan oleh Barat pada masa kini terutamanya melalui dunia percetakan dan teknologi. Teks kesusasteraan merupakan pembicara yang sentiasa ingin melihat bangsanya berada dalam konteks pemikiran dan pemahaman yang benar mengikut zamannya (2012).

Sehubungan itu juga, kajian mendapati bahawa motif ikan todak telah digunakan oleh penyair sebagai langkah percubaannya untuk mengilustrasikan permasalahan sejarah yang pernah berlaku. Kekerapan penghadiran motif ikan todak ini di dalam puisi-puisi kajian membuatkan pembaca kini teringat kepada satu peristiwa pengadilan moral yang pernah berlaku dalam lipatan sejarah bangsa suatu ketika dahulu sepertimana yang tercatat di dalam Sejarah Melayu. Justeru itu, puisi merupakan saluran utama penyair untuk memaparkannya. Hal ini kerana puisi merupakan wacana yang berkesan untuk menyampaikan idea penyair dalam kalangan masyarakat yang pelbagai lapisan. Keprihatinan penyair dengan kesan kolonialisasi selepas kemerdekaan hingga kini menjadi kayu ukur kepada penggunaan motif ikan todak di dalam puisi-puisinya. Bagi penyair, kemewahan yang dinikmati oleh generasi muda kini yang tidak didasarkan kepada kekuatan ajaran agama telah menghanyutkan mereka dengan norma-norma kebaratan, lantaran kian melupakan penat jerih perjuangan nenek-moyang mereka dalam sejarah pembangunan negara dahulu hingga kini. Bertolak daripada pemerhatian tersebut, perkaitan antara motif ikan todak dengan peristiwa sejarah telah berlaku, disusun oleh penyair dengan kata-kata yang puitis hingga mampu memberi kesan kepada khalayak seperti yang ditemui dalam puisi "Perarakan Suku Abad" (1985). Motif ikan todak yang ditemui dalam baris puisi kajian di atas misalnya berbunyi, "oleh serangan todak atau sikap antiintelektualisme". Seterusnya motif ikan todak ini hanya terus mendapat kesedaran penyair untuk dinukilkan kembali setelah dua puluh tahun kemudiannya dalam puisi berjudul "Mimpi Paduka Raja" (2005) dan "Mengenang Temasik" (2005). Dalam puisi "Mimpi Paduka Raja", kajian telah menemui motif ikan todak diungkapkan sebanyak tiga kali. Antaranya baris "apakah pulau melupai todak", dan "sedang todak tidak melupai pulau". Seterusnya motif ikan todak dijelmakan pula secara tunggal dalam puisi "Mengenang Temasik, misalnya "todak" dengan nada ketegasan. Kekerapan penjelmaan motif ini memperlihatkan wujud satu ketegasan dalam diri penyair tentang mesej yang ingin diungkapkan untuk tatapan lingkungan masyarakatnya.

Selain itu, penyair juga telah menghidupkan kembali motif tradisi seperti keris Taming Sari. Keris Taming Sari adalah simbolik kepada keunggulan kerajaan Kesultanan Melayu. Keris Taming Sari adalah lambang jatuh bangun kerajaan Kesultanan Melayu. Kehebatan Keris Taming Sari terserlah apabila alat kebesaran ini menjadi rebutan antara pahlawan Majapahit iaitu, Taming Sari dengan Hang Tuah. Keris Taming Sari merupakan anugerah Raja Majapahit kepada Laksamana Hang Tuah kerana telah berjaya mengalahkan pahlawan Majapahit, iaitu Taming Sari. Justeru itu, keris Taming Sari dan watak Hang Tuah adalah sinonim. Dalam erti kata lain, kehebatan dan keunggulan Hang Tuah berdiri di sebalik kehebatan fungsi keris tersebut. Motif keris Taming Sari ditonjolkan kembali oleh penyair buat pertama kali di dalam puisi "Bendahara, Tuah, dan Jebat, Aku Selalu Bertanya" (1994) dalam ungkapan "Tuah merampas taming sari", "Jebat, kau sepatutnya bertahan dengan taming sari", "kerana dengan keris itu kau tidak terkalahkan", dan " atau si Jebat terus bertahan dengan taming sari”. Untuk puisi kajian bagi tahun berikutnya, motif ini turut ditonjolkan malahan ditegaskan penayangannya sebanyak dua kali, iaitu di dalam puisi berjudul "Keris Taming Sari" (2005), misalnya memetik baris "Tuanku, tanpa Taming Sari itu", "dan merampas Taming Sari”, "Taming Sari membuat penentuan", "Taming Sari keris pusaka". Manakala menerusi puisi "Dang Wangi" (2005) pula dapat dilihat pada ungkapan "bertemu dihujung Taming Sari". Melalui bacaan secara pascakolonial, penghadiran semula 
kisah Taming Sari itu bertujuan menguar-uarkan kekuatan masyarakat peribumi supaya bangsa asing tidak memandang rendah akannya.

Manakala Bukit Siguntang Mahameru dimunculkan kembali oleh penyair sebagai peringatan kepada masyarakat kini tentang asal-usul peribumi. Kisah Bukit Siguntang Mahameru diungkapkan kembali oleh penyair adalah untuk membuktikan kepada penjajah bahasa masyarakat peribumi ini berasal daripada keturunan yang hebat. Malah, dengan bahasa perlambangan iaitu, simbol "bukit" yang digunakan penyair itu menunjukkan bahawa penyair meletakkan kedudukan peribumi pada tingkat yang tinggi. Ukuran ketinggian dan kemuliaan peribumi itu disamakan dengan ketinggian puncak Bukit Siguntang tersebut. Bagi mengingatkan peribumi kini tentang kehebatan asal muasal mereka, penyair telah mengungkapkan kembali peristiwa ini misalnya melalui puisi "Kemerdekaan" (1994); "bermula kini ikrar setia di Bukit Siguntang", dan dalam puisi "Melaka" (2000), dengan kata-kata "dari benih Bukit Siguntang. Penyair terus meletakkan motif "Bukit Siguntang Mahameru" sebagai suatu peringatan kepada generasi muda pada masa kini. Hal ini jelas apabila motif ini kerap ditonjolkan semula dalam puisi-puisi kajian yang dihasilkan dalam antologi Salasilah (2005) seperti menerusi puisi "Tun Seri Lanang" (2005) dengan baris "dari Bukit Siguntang ke Melaka", manakala dalam puisi "Kilauan Emas Bukit Siguntang" (2005) pula, motif ini diujarkan sebanyak dua kali alam berbentuk pengulangan fakta yang sama iaitu, "di atas Bukit Siguntang", dan "di atas Bukit Siguntang". Selanjutnya dipaparkan dalam baris puisi "Menyusur Jejak" (2005), dan "Salasilah" (2005), masing-masing melalui kata-kata berikut: "dari Bukit Siguntang Mahameru" dan "turun di Bukit Siguntang". Dalam puisi "Demang Lebar Daun" pula, motif ini dipaparkan sebanyak dua kali iaitu "Dari Bukit Siguntang ke Palembang" dan "di Bukit Siguntang Mahameru". Demikianlah, secara tidak langsung, pemaparan semula kedua-dua motif tradisi ini dan perkaitannya dengan sejarah, sedikit sebanyak mengukuhkan jati diri masyarakat peribumi kerana asal muasal mereka begitu hebat.

Penyair tidak terlepas pandang untuk turut memasukkan motif pohon Melaka dalam puisi kajian. Motif pohon Melaka ini menjelaskan lagi motif kepenyairan penyair untuk menukilkan episod sejarah yang pernah berlaku untuk tatapan generasi kini sebagai penyataan pascakolonial. Pohon Melaka diungkapkan dalam puisi "Menyusur Jejak" (2005), misalnya dengan kata-kata "di bawah pohon Melaka". Manakala, dalam puisi "Mencari Pohon Melaka" (2005) pula, kajian cuba memetik kata-kata "kucari pohon Melaka" dan "kutemui pohon Melaka". Selain itu, "Gunung Ledang" juga mendapat perhatian penyair untuk menonjolkan penggunaan motif tradisi mampu menjulang kembali fungsi sastera tradisi dalam masyarakat kini. Gunung Ledang merupakan mitos tradisi yang dibangunkan melalui peristiwa peminangan Puteri Gunung Ledang oleh Sultan Mahmud Shah pada zaman kesultanan Melayu Melaka. Namun demikian, kajian mendapati motif ini telah ditinjolkan oleh penyair buat pertama kalinya dalam puisi "Pesanan Puteri Gunung Ledang kepada Sultan Mahmud" (1994). Seterusnya motif ini kerap ditayangkan oleh penyair dalam puisi-puisi kajian yang disiarkan melalui antologi Salasiah (2005). Kekerapan penayangan motif ini dapat dilihat misalnya melalui puisi "Sebuah Balai di Gunung Ledang" (2004); "mendaki Gunung Ledang" dan "Menghadap balai di Gunung Ledang". Berikutnya, dalam anotologi yang sama juga, motif ini ditemukan oleh penyair dalam puisi "Pantun Gunung Ledang" (2004); misalnya " Gunung Ledang gunung lagenda", dan dalam puisi " Orang Tua dan Gunung Ledang" (2004), kekerapan penggunaan motif ini semakin meningkat apabila ianya diungkapkan oleh penyair sebanyak empat kali berbanding puisi lain. Hal ini dapat dilihat berdasarkan petikan baris puisi-puisi ini, "menghadap ke Gunung Ledang", "setiap kali memandang Gunung Ledang", "mereka diperintah ke Gunung Ledang", dan "Gunung Ledang masih berdiri tenang".

Akhirnya kajian mendapati Sejarah Melayu juga disebut-sebut oleh penyair dalam beberapa buah puisi kajian. Motif Sejarah Melayu sebagai sebuah karya agung yang merakamkan susur galur sejarah Tanah Melayu disebut dalam puisi "Pada Hari Keputeraan" (2000) berbunyi, "Kisah sedih Sejarah Melayu". Manakala dalam antologi yang sama juga, motif ini disebut untuk kedua kalinya melalui puisi "Melayu Itu Tanah Mu" (2000) melalui baris kata "Kubuka Kitab tua Sejarah Melayu", dan "Kisah sedih Sejarah Melayu". Justeru, untuk memaknakan peribadi seorang raja, unsur-unsur mitos dan legenda dimasukkan bagi memenuhi tujuan mendaulatkannya dan mengkritik secara halus mengenai perilaku rajanya. Unsur-unsur seperti inilah yang menjadikan teks sastera sejarah begitu unik dan istimewa (Norazimah Zakaria, Abdul Halim Ali, Azhar Wahud dan Ani Omar, 2018). 
Bertolak daripada penggunaan motif alam dalam puisi-puisi kajian, sedikit sebanyak telah melahirkan bahasa yang begitu puitis, sensitif dan sesuai untuk menggambarkan perasaan yang dialami oleh penyair pada ketika puisi-puisi itu dihasilkan, bagi menggambarkan peristiwa silam yang melatari masyarakatnya. Malahan kepuitisan bahasa yang sering kali diguna pakai oleh penyair dalam puisipuisi kajian ini telah menyebabkan Zurinah Hassan disifatkan sebagai seorang penyair yang berjaya dalam memperlihatkan sesuatu emosi atau perasaan dengan menggunakan bahasa yang indah. Ini berdasarkan kata-katanya di bawah;

"Zurinah secara keseluruhannya dapat dianggap sebagai penyair yang telah cukup baik menguasai bahasa dan pintar membentuk imajan dalam puisi. Fikiran dan gagasan yang ingin disampaikan selalu beriringan dengan perasaan yang lembut dan ini memberikan kesan kuat terhadap karyanya." (1981).

Berdasarkan pandangan di atas, nyata dan jelas sekali bahawa Zurinah Hassan merupakan seorang penyair yang sering mengungkapkan sesuatu yang ingin disampaikannya dengan menggunakan bahasa yang lembut, indah, serta kata-kata yang puitis dan ini boleh menyebabkan puisi-puisi kajian kelihatan nilai estetikanya.

\section{Kesimpulan}

Dapatlah dirumuskan bahawa Zurinah Hassan merupakan seorang penyair yang jelas gagasannya, membawa sesuatu yang baru dalam puisi-puisi terpilih yang dibincangkan. Kejelasan pemikiran penyair ini terserlah apabila beliau berjaya membawa pengucapan tradisi yang bersifat konvensi ke dalam pengucapan kini sebagai satu pernyataan pascakolonial. Tindakan ini dapatlah disifatkan sebagai satu anjakan tradisi apabila penyair telah membawa masuk sesuatu yangg berunsur tradisi untuk digayakan dalam pengucapan kini dengan bahasa kebangsaan sebagai medium penyampaiannya. Impaknya, setiap puisi yang dibicarakan dalam makalah ini jelas memperlihatkan wujud saling pinjam-meminjam antara unsur tradisi dengan unsur modeniti. Jelas di sini menunjukkan bahawa puisi-puisi yang dibincangkan memperlihatkan suatu pencarian yang bermula dari akar umbi dan tradisi bangsa. Dengan erti kata lain, Zurinah Hassan cuba menyesuaikan rentak, cita rasa dan pujangga silam bagi mewarnai dan mengarahkan kepada perpuisian kini. Penggayaan sedemikian dapat ditafsirkan sebagai tindakan pascakolonial, pertamanya kerana Zurinah Hassan cuba mengungkap kembali unsur tradisi sebagai pengucapan moden yang bertujuan sebagai kelangsungan sastera tradisi yang sekian lama dimendapkan oleh penjajah di bawah wacana kolonial dan keduanya pengungkapan kembali unsur tradisi dalam pengucapan moden itu dapat disifatkan sebagai wacana balas yang dicipta untuk menterbalikkan wacana kolonial yag menjadi sanjungan hingga kini.

\section{Rujukan}

Abdul Halim Ali. (2012). Satu Analisis Pengkisahan Semula Sastera Melayu. Jurnal Perspektif, 4(2), 16-27.

Norazimah bt Zakaria, Abdul Halim bin Ali, Azhar bin Wahid \& Ani bt Omar. (2018). Sejarah Melayu Sebagai Lambang Tradisi Akal Budi Bangsa Yang Tinggi. JMS, 1(1), 191-209

Safian Hussain (et.al.). (1998). Glosari Istilah Kesusasteraan. Kuala Lumpur: Dewan Bahasa Dan Pustaka.

Shamsul Amri (penyunting). (2005). "Shamsul Amri Baharuddin" dalam Mohamad Daud Mohamad dan Zabidah Yahya (penyelenggara) Pascakolonialisme dalam Pemikiran Melayu. Kuala Lumpur: Dewan Bahasa Dan Pustaka.

Tengku Intan Marlina Tengku Mohd Ali. (2017). rogram Kesusasteraan Melayu di Akademi Pengajian Melayu, Universiti Malaya: Pelaksanaan dan Cabaran. Jurnal Melayu, 16(1), 19-31.

Wahab Ali (1995). The Uses And Reuses Of Traditional Elements In Modern Malay Literature With Special ReferenceTo Balada Tun Fatimah" kertas kerja dalam Conference of the European Association for South EsatAsian Studies, 1-29 June- 1 July 1995. Netherlands: Universitybof Leiden. 
DOI: https://doi.org/10.47405/mjssh.v6i10.1109

Zawiyah Yahaya. (1994). Budaya Tempatan Sebagai Sistem Perlambangan untuk Menginterprestasi Sastera Kolonialis" dalam S. Jaafar Husin (penyelenggara). Pengantar Kesusasteraan Bandingan. Kuala Lumpur: Dewan Bahasa Dan Pustaka. Hal. 106.

Zurinah Hassan. (1967). Sesayup Jalan. Kuala Lumpur: Dewan Bahasa Dan Pustaka.

Zurinah Hassan. (1985). Keberangkatan. Kuala Lumpur: Dewan Bahasa Dan Pustaka.

Zurinah Hassan. (1994). Pujangga Tidak Bernama. Kuala Lumpur: Dewan Bahasa Dan Pustaka.

Zurinah Hassan. (2000). Nota Waktu. Kuala Lumpur: Dewan Bahasa Dan Pustaka.

Zurinah Hassan. (2004). Kumpulan Puisi dari Gunung Ledang: A message from Mount Ledang: An Anthologyof Poems. Kuala Lumpur: Dewan Bahasa Dan Pustaka.

Zurinah Hassan. (2005). Salasilah. Kuala Lumpur: Dewan Bahasa Dan Pustaka. 